Article

\title{
Nutritional Composition, Total Phenolic Content, Antioxidant and $\alpha$-Amylase Inhibitory Activities of Different Fractions of Selected Wild Edible Plants
}

\author{
Ziaul Hasan Rana ${ }^{1, *}$, Mohammad Khairul Alam ${ }^{2}$ iD and Mohammad Akhtaruzzaman ${ }^{2}$ \\ 1 Department of Nutritional Sciences, Texas Tech University, Lubbock, TX 79409, USA \\ 2 Institute of Nutrition and Food Science, University of Dhaka, Dhaka-1000, Bangladesh \\ * Correspondence: ziaul.h.rana@ttu.edu; Tel.: +1-(806)-500-9335
}

Received: 16 June 2019; Accepted: 29 June 2019; Published: 1 July 2019

check for updates

\begin{abstract}
Wild plants are considered the richest source of essential nutrients and other beneficial phytochemicals. Hence, the objective of this study was to evaluate the nutritional composition, antioxidant- and $\alpha$-amylase inhibition activities of leaves and roots of selected Bangladeshi wild plants. These wild plants were found to have high fiber (13.78-22.26 g/100 g), protein (7.08-21.56 g/100 g) and ash (8.21-21.43 g/100 g) contents. The total phenolic and total flavonoid contents were significantly higher in the leaves than the roots. Additionally, antioxidant activity was evaluated using ferric-reducing antioxidant power, 2, 2-diphenyl-1-picrylhydrazyl radical (DPPH) and trolox equivalent antioxidant capacity assays and was strongly correlated with phenolic compounds. The leaf extracts of the selected plants also exhibited potent $\alpha$-amylase inhibition $(\sim 71 \%)$ and were significantly higher than their root counterparts. Thus, the study findings concluded that the investigated plants were good sources of fiber, protein, mineral, natural antioxidant compounds and $\alpha$-amylase inhibitors, and their increased intake could provide health benefits. The principal component analysis (PCA) of analyzed variables divided the samples into three clear groups, and the first two principal components accounted for $86.05 \%$ of the total data set variance.
\end{abstract}

Keywords: antioxidants; $\alpha$-amylase; Bangladesh; nutritional profile; total phenolic content; wild plants

\section{Introduction}

Vegetables are an integral part of the daily human diet and provide essential nutrients (vitamins and minerals) required for active and healthy life. They are a locally available and cheap source of nutrient-dense foods and considerably contribute to human health, nutrition and food security. The edible parts of vegetable plants include the leaves, roots, stems, fruits or seeds, and they can be consumed cooked as well as in raw forms. Evidence from epidemiological studies indicate that daily consumption of fruits and vegetables is correlated with a lower prevalence of many chronic diseases, including diabetes, infections, cardiovascular and neurological disorders and cancers [1-3]. Wild vegetables are considered to be a potential source of essential nutrients such as vitamin $C$, minerals, vitamins, proteins, fibers [4-6] and are also good dietary sources of antioxidants such as flavonoids and other polyphenolic constituents [4,7].

A diet low in antioxidants and high in processed foods (e.g., red meat) can augment the production of endogenous reactive oxygen species (ROS) [8-10] which can lead to many of the chronic diseases stated above [11]. This demonstrates the need for natural antioxidant compounds which can prevent the overproduction of ROS. It has been shown that there is an inverse relationship between morbidity and mortality from degenerative disorders and the ingestion of natural antioxidants [12]. Currently, 
wild or traditional plants, as a source of natural antioxidants, have received increased attention because of their ability to scavenge ROS and also as sources of trace elements, and their additional health properties, such as antidiabetic, antibacterial and anticancer activity, make them valuable for incorporation into the daily diet [13-16].

Phenolic compound-rich food consumption has also been shown to be inversely associated with type-2 diabetes [17]. By binding to the non-specific site of the enzyme, phenolic compounds can inactivate the starch-digesting enzyme $\alpha$-amylase [18]. Thus, wild edible plants, as a source of high phenolic compounds, can inhibit $\alpha$-amylase activity which subsequently decreases postprandial rises in blood glucose by suppressing the rate of glucose release and absorption in the small intestine [19].

Several wild edible plants are traditionally consumed along with staple foods, especially in rural areas and a few urban communities, in Bangladesh. These plants play a vital role in fulfilling the demand for nutritional, minerals and antioxidant compounds in the diet of indigenous communities [4,20]; besides these factors, they are also used in treating certain medical conditions, for example, diabetes, in these local tribes [21]. However, there is lack of information about the nutritional composition of wild edible plants in Bangladesh and their ability to inhibit digestive enzymes. Therefore, the aim of this study was to assess the proximate and mineral composition, antioxidant potential, and $\alpha$-amylase inhibition activity of the leaves and roots of three indigenous wild edible plants (Achyranthes aspera L., Eclipta alba L., and Vitex negundo L.) consumed by different local communities in Bangladesh. The findings of the present study will provide the preliminary data on the nutritional and neutraceutical potential of wild edible plants in Bangladesh and thus could be incorporated into food composition databases and used for further utilization as dietary supplements and/or functional foods.

\section{Materials and Methods}

\subsection{Reagents}

Analytical-grade acetone, petroleum ether, n-hexane, dichloromethane, sodium carbonate, Folin-Ciocalteu reagent and acetic acid were purchased from Merck (Darmstadt, Germany). Gallic acid (Pub Chem CID:370) was purchased from Tokyo Chemical Industry Co., (Tokyo, Japan) and 2,20-azinobis (3-ethylbenothiazoline-6-sulfonic acid) diammonium salt (ABTS) was purchased from Wako Pure Chemical Industries, Ltd. (Osaka, Japan). $\alpha$-amylase, 2, 2-diphenyl-1-picrylhydrazyl radical (DPPH), Tri(2-pyridyl)-s-triazine (TPTZ), trolox, potassium persulfate, and mineral standards were obtained from Sigma Aldrich (Steinheim, Germany). All chemicals used for the analysis were of analytical grade.

\subsection{Sample Collection and Preparation}

To determine the proximate and mineral composition, total phenolic contents (TPC), total flavonoid contents (TFC), antioxidant capacities (DPPH, ferric-reducing antioxidant power (FRAP) and trolox equivalent antioxidant capacity (TEAC)), and $\alpha$-amylase inhibition activity, three wild plant samples were collected from different locations in Bangladesh. Two to three samples (300-600 g) were collected for each of the wild plants from every growing location. These were then mixed to make three analytes or composite test samples. The study samples were Achyranthes aspera L. (Upat Lengra), Eclipta alba L. (Kalokeshi), and Vitex negundo L. (Nirgundi). The samples were selected based on their traditional use, by interviewing local people, in treating diabetes. The identification of the samples was confirmed by a taxonomist of the Department of Botany, University of Dhaka, who accompanied the collection team, after examining the morphological characteristics. Photographs of these samples are shown in Figure 1. After collection, the leaves and roots of the samples were separated and gently washed with tap water immediately to remove sand and other extraneous material before being washed with distilled water and then air-dried. Then, the samples were cut into small pieces and freeze-dried (il Shin lab.Co. Ltd., Korea). The freeze-dried samples were ground and homogenized into a fine powder using a grinder. 
The homogenized samples were sieved to obtain an even particle size, then placed in an air-tight zipper bag and stored at $-20{ }^{\circ} \mathrm{C}$ until further analysis.
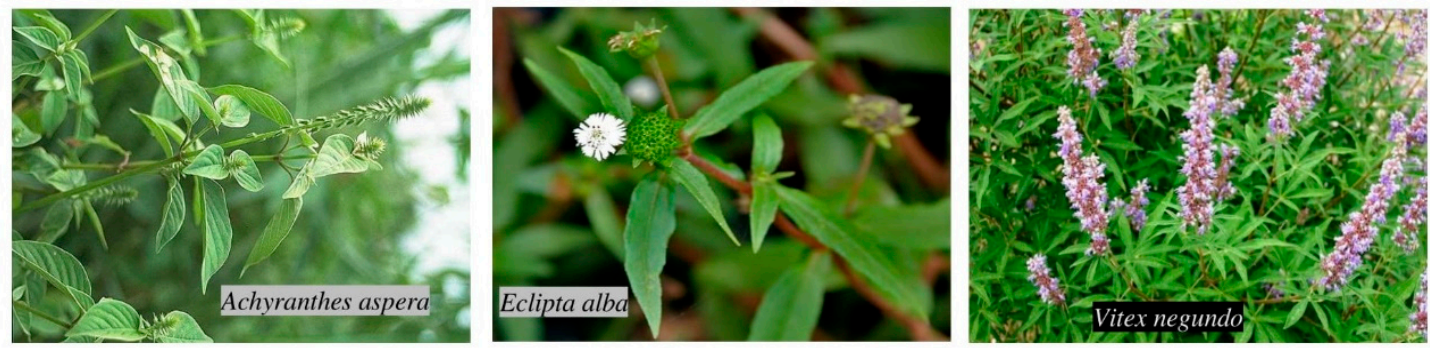

Figure 1. Photograph of selected samples.

\subsection{Determination of Proximate Composition}

The proximate composition (moisture, total protein, total fat, total dietary fiber including soluble and insoluble, ash and total available carbohydrate content) of the selected samples was estimated according to the method described previously [22]. Moisture and ash contents of the sample were calculated by the weight difference method, whereas the total fat content of the samples was estimated by the Association of Official Analytical Chemists (AOAC) method using petroleum ether as solvent. The total protein content was determined by using the micro-Kjeldhal method (nitrogen content of the samples $\times 6.25$ ). The gravimetric method was utilized for the estimation of total dietary fiber (soluble and insoluble). Total available carbohydrate contents were calculated by difference using the formula below:

Carbohydrate content $(\%)=100-[$ total protein $(\%)+$ ash content $(\%)+$ total fat $(\%)+$ total fiber $(\%)]$.

\subsection{Determination of Mineral Composition}

Mineral concentrations in the plants sample were calculated by using an atomic absorption spectrophotometric method described previously [23]. Briefly, approximately $500 \mathrm{mg}$ of plant samples after drying were subjected to wet digestion with nitric acid and perchloric acid (2:1 ratio) in an auto-digestor at $325^{\circ} \mathrm{C}$ to accelerate the discharge of mineral in the plant matrix. After digestion and appropriate dilution, the digested sample was aspirated into an air-acetylene flame to burn the elements into atomic components, which were then detected in a spectrophotometer at their relevant wavelengths. Proportions of calcium, magnesium, sodium, zinc, copper and iron were evaluated by atomic absorption spectrophotometry (Model-AA-7000S, Shimadzu, Tokyo, Japan). The amount of potassium was determined by flame photometry (Jenway flame photometer model PFP7, Origin UK). A standard calibration curve was plotted for each of the minerals using the respective mineral standard obtained from Sigma Chemical Co., USA.

\subsection{Plant Extraction}

The extraction of plants was carried out according to the previously described procedure using methanol and $1 \mathrm{~N} \mathrm{HCl}$ [24], and the extract was stored at $4{ }^{\circ} \mathrm{C}$ for the determination of $\mathrm{TPC}, \mathrm{TFC}$, antioxidant activity and $\alpha$-amylase activity.

\subsection{Determination of Total Phenolic Content}

The TPC in plant extracts was estimated by the Folin-Ciocalteu colorimetric method as described previously [22,24]. Briefly, for each sample, $150 \mu \mathrm{L}$ of plant extracts were taken in test tubes. To this, $900 \mu \mathrm{L}$ distilled water was added. $225 \mu \mathrm{L}$ of diluted Folin-Ciocalteu reagent (2-fold) was added to the solution and allowed to stand for $5 \mathrm{~min}$ at room temperature. Then, $1.125 \mathrm{~mL}$ of $2 \% \mathrm{Na}_{2} \mathrm{CO}_{3}$ solution was added, mixed well and left for $15 \mathrm{~min}$ at room temperature. Finally, the absorbance was 
measured at $750 \mathrm{~nm}$ by a UV-VIS spectrophotometer (UV-1800, Shimadzu, Kyoto, Japan). The TPC was calculated using a standard curve based on gallic acid. Results were expressed as milligrams of gallic acid equivalent (GAE) per gram dry weight (DW) (mg GAE/g DW).

\subsection{Determination of Total Flavonoid Content}

The TFC was estimated by means of the colorimetric method according to Miao et al. [25] with slight modification. Briefly, $250 \mu \mathrm{L}$ of the extract was mixed with $1.125 \mathrm{ml}$ of distilled water in a test tube. To these, $75 \mu \mathrm{L}$ of $5 \% \mathrm{NaNO}_{2}$ solution was added. After 6 min, $150 \mu \mathrm{L}$ of $10 \% \mathrm{AlCl}_{3} \cdot 6 \mathrm{H}_{2} \mathrm{O}$ solution was added. The solution was left to stand for another $5 \mathrm{~min}$, and $500 \mu \mathrm{L}$ of $1 \mathrm{M} \mathrm{NaOH}$ was added. Finally, the mixture was vortexed, and the absorbance was measured immediately at $510 \mathrm{~nm}$ by a UV-VIS spectrophotometer (UV-1800, Shimadzu, Kyoto, Japan). The TFC in the plant extract was calculated using a standard curve based on quercetin and results were expressed as milligrams quercetin equivalent (QE) per gram of dry weight (mg QE/g DW).

\subsection{Evaluation of Antioxidant Capacities}

\subsubsection{DPPH Free Radical Scavenging Assay}

The antioxidant activity of the plant extracts was evaluated by utilizing 2,2-diphenyl-1 -pycrylhydrazyl (DPPH) free radical according to Alam et al. [24]. The DPPH free radical inhibition capacity was calculated according to the following equation:

$$
\% \text { DPPH inhibition }=\left(\left(1-\left(\left(\mathrm{Abs}_{\text {sample }}-\mathrm{Abs}_{\text {blank }}\right) /\left(\mathrm{Abs}_{\mathrm{control}}-\mathrm{Abs}_{\text {blank }}\right)\right)\right) \times 100\right.
$$

where $\mathrm{Abs}_{\text {blank }}$ is the absorbance of the blank (containing only methanol), $\mathrm{Abs}_{\text {control }}$ is the absorbance of the control reaction (containing all reagents minus plant extracts), and $\mathrm{Abs}_{\text {sample }}$ is the absorbance of the plant extracts. The plant extract concentration required for the $50 \%$ inhibition of DPPH free radical $\left(\mathrm{IC}_{50}\right)$ was estimated from the dose-response graph plotted with percentage inhibition and concentrations of plant extract.

\subsubsection{Ferric Reducing Antioxidant Power (FRAP) Assay}

This assay was carried out according to Miao et al. [25] with little modification. Briefly, the FRAP reagent was made from by combining $10 \mathrm{mmol} / \mathrm{L} \mathrm{2,4,6-tripyridyls-triazine} \mathrm{(TPTZ)} \mathrm{solution,} 300 \mathrm{mmol} / \mathrm{L}$ acetate buffer ( $\mathrm{pH} 3.6$ ), and $20 \mathrm{mmol} / \mathrm{L} \mathrm{FeCl}_{3}$ solution in a ratio of 1:10:1 (v/v), respectively. The FRAP reagent was freshly prepared and was incubated at $37^{\circ} \mathrm{C}$ in a water bath before using. $100 \mu \mathrm{l}$ of plant extracts were added to $3 \mathrm{~mL}$ of the FRAP reagent. The mixture was vortexed, and absorbance of the solution was then measured at $593 \mathrm{~nm}$ (UV-1800, Shimadzu, Kyoto, Japan) after incubating at $37^{\circ} \mathrm{C}$ for $30 \mathrm{~min}$. Various concentrations $(50-600 \mu \mathrm{mol} / \mathrm{L})$ of $\mathrm{Fe}^{2+}$ solution was used to prepare the standard curve. The results were expressed as $\mu \mathrm{mol} \mathrm{Fe}{ }^{2+}$ per gram of dry weight $\left(\mu \mathrm{mol} \mathrm{Fe} \mathrm{F}^{2+} / \mathrm{g} \mathrm{DW}\right)$.

\subsubsection{Trolox Equivalent Antioxidant Capacity (TEAC) Assay}

This assay was performed by the advanced $\mathrm{ABTS}^{\bullet+}$ method as described by Miao et al. [25] with little modification. $\mathrm{ABTS}^{\bullet+}$ radical cation was produced by dissolving ABTS and potassium persulfate in distilled water to give a final concentration of $7 \mathrm{mmol} / \mathrm{L}$ and $2.45 \mathrm{mmol} / \mathrm{L}$, respectively. The solutions were mixed, and the reaction mixture was left in the dark at room temperature for $24 \mathrm{~h}$. The ABTS ${ }^{\bullet+}$ solution was diluted with distilled water to an absorbance of $1.00 \pm 0.03$ at $734 \mathrm{~nm}$. Then, $100 \mu \mathrm{L}$ of plant extracts were added to $3.8 \mathrm{~mL}$ of diluted $\mathrm{ABTS}^{\bullet+}$ solution and the solutions were kept in the dark for $10 \mathrm{~min}$. After $10 \mathrm{~min}$, the absorbance was read at $734 \mathrm{~nm}$ by a UV-VIS spectrophotometer (UV-1800, Shimadzu, Kyoto, Japan) against the blank (distilled water). The trolox solution of various concentrations (0-15 $\mathrm{mol} / \mathrm{L})$ was used to prepare the standard curve, and the results were expressed as $\mu$ mol trolox per gram of dry weight extract ( $\mu$ mol trolox/g DW). 


\section{9. $\alpha$-Amylase Inhibitory Assay}

The $\alpha$-amylase inhibitory activity of the plant samples was performed by the modified starch iodine method described by Hossain et al. [26]. Briefly, $100 \mu \mathrm{L}$ of plant extracts $(0.25 \mathrm{mg} / \mathrm{mL})$ were taken in test tubes. To each test tube, an aliquot of $2 \mu \mathrm{L}$ of $\alpha$-amylase was added and incubated for $10 \mathrm{~min}$ at $37^{\circ} \mathrm{C}$. After incubating, $1 \%$ starch solution $(20 \mu \mathrm{L})$ was added. Then, the mixture was incubated again for $60 \mathrm{~min}$ at $37^{\circ} \mathrm{C}$. After that, $20 \mu \mathrm{L}$ of $1 \%$ iodine solution was added to the mixture. The absorbance of the mixture was taken at $565 \mathrm{~nm}$, after the addition of $1 \mathrm{~mL}$ distilled water. Acarbose, a known $\alpha$-amylase inhibitor, was used as a standard. The $\alpha$-amylase inhibitory activity was calculated and expressed as percentage inhibition using the following formula:

$$
(\%) \alpha \text {-amylase Inhibition }=\left(1-\left(\mathrm{Abs}_{\text {sample }} / \mathrm{Abs}_{\text {control }}\right)\right) \times 100
$$

where $\mathrm{Abs}_{\text {control }}$ is the absorbance of the control reaction (containing all reagents minus plant extracts or acarbose) and $\mathrm{Abs}_{\text {sample }}$ is the absorbance of the plant extracts or acarbose.

\subsection{Statistical Analysis}

All experiments were carried out in three replicates and presented as mean \pm standard deviation (SD) using Minitab version 18.0. (Minitab Inc., State College, PA, USA). One-way analysis of variance (ANOVA) and principal component analysis (PCA) were performed to check the differences between the nutrient contents, TPC, TFC, antioxidant activity, and $\alpha$-amylase inhibition activity among the plant samples. The differences were declared significant at a level of $p<0.05$. The Dunnett test to compare with control for $\alpha$-amylase activity and Pearson correlation among variables were also calculated.

\section{Results and Discussion}

\subsection{Proximate Composition}

Table 1 summarizes the proximate composition, macro mineral ( $\mathrm{Ca}, \mathrm{Na}, \mathrm{K} \mathrm{Mg}$ ) and micro mineral $(\mathrm{Fe}, \mathrm{Zn}, \mathrm{Cu})$ content in the leaves and roots of the investigated wild plants.

The moisture content of the wild plants ranged from $82.78 \pm 2.68$ to $88.13 \pm 1.55 \mathrm{~g} / 100 \mathrm{~g}$ fresh weight (FW) in the leaves and $55.44 \pm 2.22$ to $70.41 \pm 2.11 \mathrm{~g} / 100 \mathrm{~g}$ FW in roots, which is in accordance with results reported by other authors [4,5]. On the other hand, Satter et al. [20] reported a higher content of moisture in some other wild plants of Bangladesh.

Protein contents were found between $18.13 \pm 1.67$ to $21.56 \pm 1.10 \mathrm{~g} / 100 \mathrm{~g} \mathrm{DW}$ in leaves and $7.08 \pm 0.33$ to $13.21 \pm 0.93 \mathrm{~g} / 100 \mathrm{~g}$ DW in roots, which is opposite to the findings of other studies [4,27]. However, our findings are similar to results observed by Satter et al. [20] and higher than those reported by Gupta et al. [5].

The contents of fat in this study were $1.88 \pm 0.20$ to $3.13 \pm 0.51 \mathrm{~g} / 100 \mathrm{~g}$ DW and $0.89 \pm 0.07$ to $1.12 \pm 0.10 \mathrm{~g} / 100 \mathrm{~g}$ DW in leaves and roots, respectively. These values are less than those reported by other authors $[4,20,27]$.

The ash contents in the leaves and roots were observed from $19.78 \pm 0.42$ to $21.43 \pm 0.33 \mathrm{~g} / 100 \mathrm{~g}$ DW and $8.21 \pm 0.61$ to $17.37 \pm 0.51 \mathrm{~g} / 100 \mathrm{~g}$ DW, respectively. Afolayan \& Jimoh [4] also reported similar values, whereas Gupta et al. [5] and Satter et al. [20] found lower contents than ours.

Dietary fiber content was in the range of $18.65 \pm 1.23$ to $20.28 \pm 0.92 \mathrm{~g} / 100 \mathrm{~g}$ DW in leaves and $13.78 \pm 1.34$ to $22.26 \pm 0.56 \mathrm{~g} / 100 \mathrm{~g}$ DW in roots, which is higher than that reported by previous studies $[4,20]$. Regional or other factors could be an explanation for these variations in proximate composition, as indicated elsewhere [22]. 
Table 1. Proximate composition (g/100g dry weight (DW)), and macro minerals and micro minerals (DW basis) of selected wild plants.

\begin{tabular}{|c|c|c|c|c|c|c|}
\hline \multirow{2}{*}{ Wild Plants } & \multicolumn{2}{|c|}{ Achyranthes aspera L. (Upat Lengra) } & \multicolumn{2}{|c|}{ Eclipta alba L. (Kalokeshi) } & \multicolumn{2}{|c|}{ Vitex negundo L. (Nirgundi) } \\
\hline & Leaves & Roots & Leaves & Roots & Leaves & Roots \\
\hline \multicolumn{7}{|c|}{ Proximate composition (g/100 g sample) } \\
\hline Moisture & $83.71 \pm 1.33$ & $61.23 \pm 1.01$ & $88.13 \pm 1.55$ & $55.44 \pm 2.22$ & $82.78 \pm 2.68$ & $70.41 \pm 2.11$ \\
\hline Protein & $18.13 \pm 1.67$ & $7.08 \pm 0.33$ & $21.56 \pm 1.10$ & $13.21 \pm 0.93$ & $19.27 \pm 0.85$ & $11.35 \pm 1.05$ \\
\hline Fat & $1.88 \pm 0.20$ & $0.89 \pm 0.07$ & $2.17 \pm 0.11$ & $0.94 \pm 0.05$ & $3.13 \pm 0.51$ & $1.12 \pm 0.10$ \\
\hline Fiber & $18.65 \pm 1.23$ & $22.26 \pm 0.56$ & $20.28 \pm 0.92$ & $16.56 \pm 0.52$ & $19.70 \pm 0.90$ & $13.78 \pm 1.34$ \\
\hline Ash & $21.43 \pm 0.33$ & $13.42 \pm 0.88$ & $19.78 \pm 0.42$ & $17.37 \pm 0.51$ & $20.15 \pm 0.75$ & $8.21 \pm 0.61$ \\
\hline Carbohydrate $(\mathrm{CHO})$ & $39.91 \pm 1.85$ & $56.35 \pm 1.46$ & $36.21 \pm 0.63$ & $51.92 \pm 1.50$ & $37.75 \pm 0.75$ & $65.54 \pm 1.78$ \\
\hline \multicolumn{7}{|c|}{ Mineral Composition } \\
\hline \multicolumn{7}{|c|}{ Macro minerals (mg/100 g sample) } \\
\hline Sodium (Na) & $497.51 \pm 3.66$ & $135.20 \pm 1.03$ & $345.33 \pm 1.25$ & $100.50 \pm 0.70$ & $577.82 \pm 2.23$ & $202.72 \pm 1.08$ \\
\hline Potassium (K) & $4866.45 \pm 5.78$ & $1185.37 \pm 1.75$ & $5174.82 \pm 5.74$ & $2359.90 \pm 4.01$ & $3345.20 \pm 4.65$ & $1058.39 \pm 5.05$ \\
\hline Magnesium (Mg) & $333.51 \pm 2.43$ & $164.38 \pm 0.96$ & $274.20 \pm 3.98$ & $148.21 \pm 2.22$ & $315.15 \pm 2.45$ & $190.80 \pm 0.70$ \\
\hline Calcium (Ca) & $1493.45 \pm 3.73$ & $842.16 \pm 2.02$ & $2221.33 \pm 6.83$ & $523.91 \pm 1.13$ & $1786.24 \pm 7.88$ & $1090.90 \pm 1.10$ \\
\hline \multicolumn{7}{|c|}{ Micro minerals (mg/100 g sample) } \\
\hline Iron $(\mathrm{Fe})$ & $31.61 \pm 0.70$ & $19.83 \pm 1.33$ & $45.22 \pm 1.12$ & $16.13 \pm 0.80$ & $62.05 \pm 1.01$ & $23.40 \pm 0.9$ \\
\hline Zinc $(\mathrm{Zn})$ & $6.03 \pm 0.09$ & $3.51 \pm 0.05$ & $5.82 \pm 0.96$ & $2.80 \pm 0.09$ & $5.88 \pm 0.44$ & $4.35 \pm 0.65$ \\
\hline Copper $(\mathrm{Cu})$ & $1.13 \pm 0.02$ & $0.51 \pm 0.01$ & $2.33 \pm 0.07$ & $0.67 \pm 0.03$ & $1.08 \pm 0.04$ & $0.84 \pm 0.02$ \\
\hline
\end{tabular}


Amounts of total available carbohydrate $(\mathrm{CHO})$ were documented to be $36.21 \pm 0.63$ to $39.91 \pm 1.85 \mathrm{~g} / 100 \mathrm{~g}$ DW in leaves and $51.92 \pm 1.50$ to $65.54 \pm 1.78 \mathrm{~g} / 100 \mathrm{~g}$ DW in roots. Satter et al. [20] found higher values of total $\mathrm{CHO}$ in the leaves of other wild plants of Bangladesh, whereas Afolayan \& Jimoh [4] and Seal [27] stated lower values than ours in South African and Indian wild edible plants. Thus, the proximate composition of wild plants grown in Bangladesh contain similar or even higher contents of specific nutrients to those of other wild plants growing in different global areas. These wild plants, as a source of high fiber, protein and ash, and with a low fat content, could be incorporated into weight control diet for obese people.

\subsection{Mineral Composition}

The mineral (macro and micro) composition of the studied wild plants is presented in Table 1, and the results revealed that these wild plants were rich in a wide variety of minerals including $\mathrm{Na}, \mathrm{K}, \mathrm{Mg}$, $\mathrm{Ca}, \mathrm{Fe}, \mathrm{Zn}$, and $\mathrm{Cu}$. Vitex negundo leaf was found to contain higher amounts of $\mathrm{Na}$ and $\mathrm{Fe}$, whereas $\mathrm{Mg}$ and $\mathrm{Zn}$ contents were higher in the leaf of Achyranthes aspera. Eclipta alba leaf was found to be a better source of potassium (5174.82 $\pm 5.74 \mathrm{mg} / 100 \mathrm{~g} \mathrm{DW})$, calcium $(2221.33 \pm 6.83 \mathrm{mg} / 100 \mathrm{~g} \mathrm{DW})$ and Cu $(2.33 \pm 0.07 \mathrm{mg} / 100 \mathrm{~g} \mathrm{DW})$ than others (Table 1$)$. The roots of the plant had a relatively lower amount of minerals than their corresponding leaves $(p<0.0001) . \mathrm{Mg}$ and $\mathrm{Cu}$ values in the plant samples were found to be comparable to the values reported by several authors [4,20]. However, the concentrations of other minerals were much higher than those reported for other wild plant varieties [20,27], and some values were less than those stated by Afolayan \& Jimoh [4]. These wild plants contain comparable or higher amounts of minerals than those documented in some commonly consumed vegetables such as spinach, cauliflower, cabbage, and lettuce and other cultivated vegetables [28]. Thus, the selected wild plants could potentially be utilized as a good source of major and trace minerals required for normal body function and maintenance.

\subsection{Total Phenolic and Flavonoid Contents}

The TPC of the leaf and root extracts of the studied plants was determined by the Folin-Ciocalteu method. The plant samples undertaken in this study showed the presence of TPC in ranges of $2.46 \pm 0.06$ to $8.45 \pm 0.15 \mathrm{mg} \mathrm{GAE} / \mathrm{g}$ DW, and $55.32 \pm 0.47$ to $72.11 \pm 0.73 \mathrm{mg}$ GAE$/ \mathrm{g}$ DW for the roots and leaves, respectively (Table 2). The leaves of the samples were higher in TPC than their roots $(p<0.0001)$. The leaf and root of Vitex negundo showed the highest $(72.11 \pm 0.73 \mathrm{mg}$ GAE/g DW) and lowest $(2.46 \pm 0.06 \mathrm{mg}$ GAE/g DW) content of TPC, respectively.

The TFC of the root and leaf extracts of the samples was estimated by flavonoid-aluminum chloride conjugation method and is presented in Table 2. The estimation of TFC in different samples revealed values from $1.22 \pm 0.09$ to $4.88 \pm 0.31 \mathrm{mg} \mathrm{QE} / \mathrm{g} \mathrm{DW}$, and $31.55 \pm 0.25$ to $80.23 \pm 0.55 \mathrm{mg}$ QE/g DW for the roots and leaves, respectively (Table 2). The highest content $(80.23 \pm 0.55 \mathrm{mg} \mathrm{QE} / \mathrm{g}$ DW) was observed in Achyranthes aspera leaf extract, while Vitex negundo root extract exhibited the lowest (1.22 $\pm 0.09 \mathrm{mg}$ QE/g DW). Like TPC, TFC was also higher in leaves than roots $(p<0.0001)$. However, some studies reported higher contents of TPC and TFC in stems and roots than leaves, which is contradictory to our observation [29]. 
Table 2. Total phenolic, flavonoid, TEAC, and FRAP contents of the selected samples.

\begin{tabular}{|c|c|c|c|c|c|c|c|c|c|c|}
\hline \multirow{2}{*}{ Scientific Name } & \multirow{2}{*}{ Family } & \multirow{2}{*}{ Local Name } & \multicolumn{2}{|c|}{$\mathrm{TPC}^{1}$ (mg GAE/g DW) } & \multicolumn{2}{|c|}{$\mathrm{TFC}^{2}$ (mg QE/g DW) } & \multicolumn{2}{|c|}{ TEAC $^{3}(\mu \mathrm{mol}$ trolox/g DW) } & \multicolumn{2}{|c|}{ FRAP $^{4}\left(\mu \mathrm{mol} \mathrm{Fe}^{2+} / \mathrm{g} \mathrm{DW}\right)$} \\
\hline & & & Leaves & Roots & Leaves & Roots & Leaves & Roots & Leaves & Roots \\
\hline Achyranthes aspera $\mathrm{L}$. & Amaranthacea & e Upat Lengra & $68.84 \pm 0.61^{\mathrm{a}}$ & $4.55 \pm 0.11^{\mathrm{b}}$ & $80.23 \pm 0.55^{\mathrm{a}}$ & $2.23 \pm 0.19^{\mathrm{b}}$ & $250.18 \pm 1.08^{\mathrm{a}}$ & $12.13 \pm 0.28^{b}$ & $505.19 \pm 1.56^{\mathrm{a}}$ & $65.22 \pm 0.70^{\mathrm{b}}$ \\
\hline Eclipta alba L. & Asteraceae & Kalokeshi & $55.32 \pm 0.47^{b}$ & $8.45 \pm 0.15^{\mathrm{a}}$ & $31.55 \pm 0.25^{\mathrm{c}}$ & $4.88 \pm 0.31^{\mathrm{a}}$ & $184.31 \pm 1.42^{b}$ & $18.58 \pm 0.20^{\mathrm{a}}$ & $474.35 \pm 1.88^{\mathrm{b}}$ & $81.05 \pm 0.55^{\mathrm{a}}$ \\
\hline Vitex negundo L. & Lamiaceae & Nirgundi & $72.11 \pm 0.73^{\mathrm{a}}$ & $2.46 \pm 0.06^{c}$ & $51.07 \pm 0.88^{b}$ & $1.22 \pm 0.09^{b}$ & $282.41 \pm 1.25^{\mathrm{a}}$ & $7.50 \pm 0.10^{\mathrm{b}}$ & $554.41 \pm 2.38^{\mathrm{a}}$ & $53.78 \pm 0.98^{c}$ \\
\hline
\end{tabular}

Values in the same column having different letters differ significantly $(p<0.05) .{ }^{1}$ Total phenolic content; ${ }^{2}$ Total flavonoid content; ${ }^{3}$ Trolox equivalent antioxidant capacity: ${ }^{4}$ Ferric reducing antioxidant power. FRAP: ferric-reducing antioxidant power; TEAC: trolox equivalent antioxidant capacity; TPC: total phenolic content: GAE: gallic acid equivalent; TFC: total flavonoid content; QE: quercetin equivalent. 
To our knowledge, there are little or no available data in the literature about the TPC and TFC of the selected plants; thus, only a few papers could be found related to the TPC and TFC of other species of the same families. The leaf extract of Vitex negundo has recently been reported to contain $89.71 \mathrm{mg} \mathrm{GAE} / \mathrm{g}$ of TPC and $63.11 \mathrm{mg}$ QE/g of TFC [30], which are relatively higher values than our study. Shahat et al. [31] reported TPC in the range from 11 to $56 \mathrm{mg} \mathrm{GAE} / \mathrm{g}$ of DW for different species of Asteraceae family, which is a lower value than our findings. Compared to a study by Nana et al. [32], using Amaranthus cruentus and Amaranthus hybridus of the Amaranthaceae family, we found lower TPC and TFC values in our sample of the Amaranthaceae family. We also found higher TPC in our study than some frequently consumed local vegetables [33]. On the other hand, our observed content was lower than some reported Asian vegetables [7,34]. However, it is well recognized that several factors, such as species, plant tissue, temperature, water stress and light conditions, as well as phenological development, can influence the TPC in the plants [22,24,35]. Thus, this explains the large differences observed between our and previous findings.

\subsection{Antioxidant Capacities}

The antioxidant capacities of the leaf and root extracts of the plants were investigated by various free radical scavenging assays, including DPPH, ABTS, and FRAP assays. In all of the antioxidant activity assays, the extract of leaves exhibited stronger antioxidant activity as compared to the extract of roots, which is in accordance with TPC and TFC.

Figure 2 represents the \% inhibition of the DPPH free radical (a) and $\mathrm{IC}_{50}$ value (b) of the leaf and root extracts. The highest DPPH inhibition (86.65\% inhibition) was observed in the Vitex negundo leaf, while the root of the same species showed the lowest inhibition (55.15\% inhibition). The leaf extracts showed more potent scavenging activity than their root counterparts $(p<0.001)$. Adedapo et al. [29] also observed a similar trend but only at higher concentrations of the extract. Antioxidant activity measured by DPPH assay in different vegetables available in the local market ranged from 0.61 to $8328.80 \mu \mathrm{mol}$ trolox equivalent per gram [33]. At $100 \mu \mathrm{g} / \mathrm{mL}$, Adedapo et al. [29] noticed an $89.7 \%$ and $67.0 \%$ inhibition of DPPH by the leaf and stem of a South African medicinal plant, respectively, while Shahat et al. [31] recorded almost 100\% inhibition of DPPH by Asteraceae family plants. Dasgupta \& De [7] reported IC $_{50}$ values of some leafy vegetables in India, measured by DPPH assay, ranging from 61.4 to $1946 \mu \mathrm{g} / \mathrm{mL}$, which are higher values than what we observed in this study.

Table 2 represents the antioxidant activity of the plant extracts (leaf and root) based on ABTS and FRAP assays. The existence of antioxidant substances or reductants in the plant extracts directs the conversion of the ferric $\left(\mathrm{Fe}^{3+}\right)$ complex to the ferrous $\left(\mathrm{Fe}^{2+}\right)$ form, which is the principle of FRAP assay. The decrease in $\mathrm{Fe}^{3+}$ in the solution leads to the decrease in color, which implies the potent reducing power of the plant extracts. Among the selected plant extracts, Vitex negundo leaf and root extracts showed the highest $(554.41 \pm 2.38)$ and lowest $(53.78 \pm 0.98)$ FRAP values, respectively (Table 2$)$.

In this study, the free radical scavenging power was also evaluated using the improved ABTS ${ }^{\bullet+}$ method. The principle behind this assay is producing the ABTS radical cation $\left(\mathrm{ABTS}^{\bullet+}\right.$ ), a blue-green chromogen, by reacting ABTS and potassium persulphate. In the presence of antioxidant components, the color of the free radical is decreased, which has a characteristic absorbance at $734 \mathrm{~nm}$ [25]. Like DPPH inhibition and FRAP, Vitex negundo leaf and root extracts also showed the highest $(282.41 \pm 1.25)$ and lowest $(7.50 \pm 0.10)$ TEAC values, respectively (Table 2). Adedapo et al. [29] reported higher values of FRAP in stem than leaves, whereas in this study, we observed the opposite. However, a similar trend to our observation was reported by Adedapo et al. [29] in terms of ABTS value. The ABTS and FRAP values in some Indian leafy vegetables varied from 18.3 to $71.8 \mu \mathrm{mol}$ trolox/g DW and 107.7 to $275.6 \mu \mathrm{mol} \mathrm{Fe}{ }^{2+} / \mathrm{g}$ DW, respectively [28]. The antioxidant competencies obtained from FRAP assay and those obtained from TEAC assay were highly correlated $(\mathrm{R}=0.988)$ (Table 3$)$, which signifies that antioxidants present in these plants were proficient in scavenging free radicals (ABTS ${ }^{\bullet+}$ ) and reducing oxidants (ferric ions). 

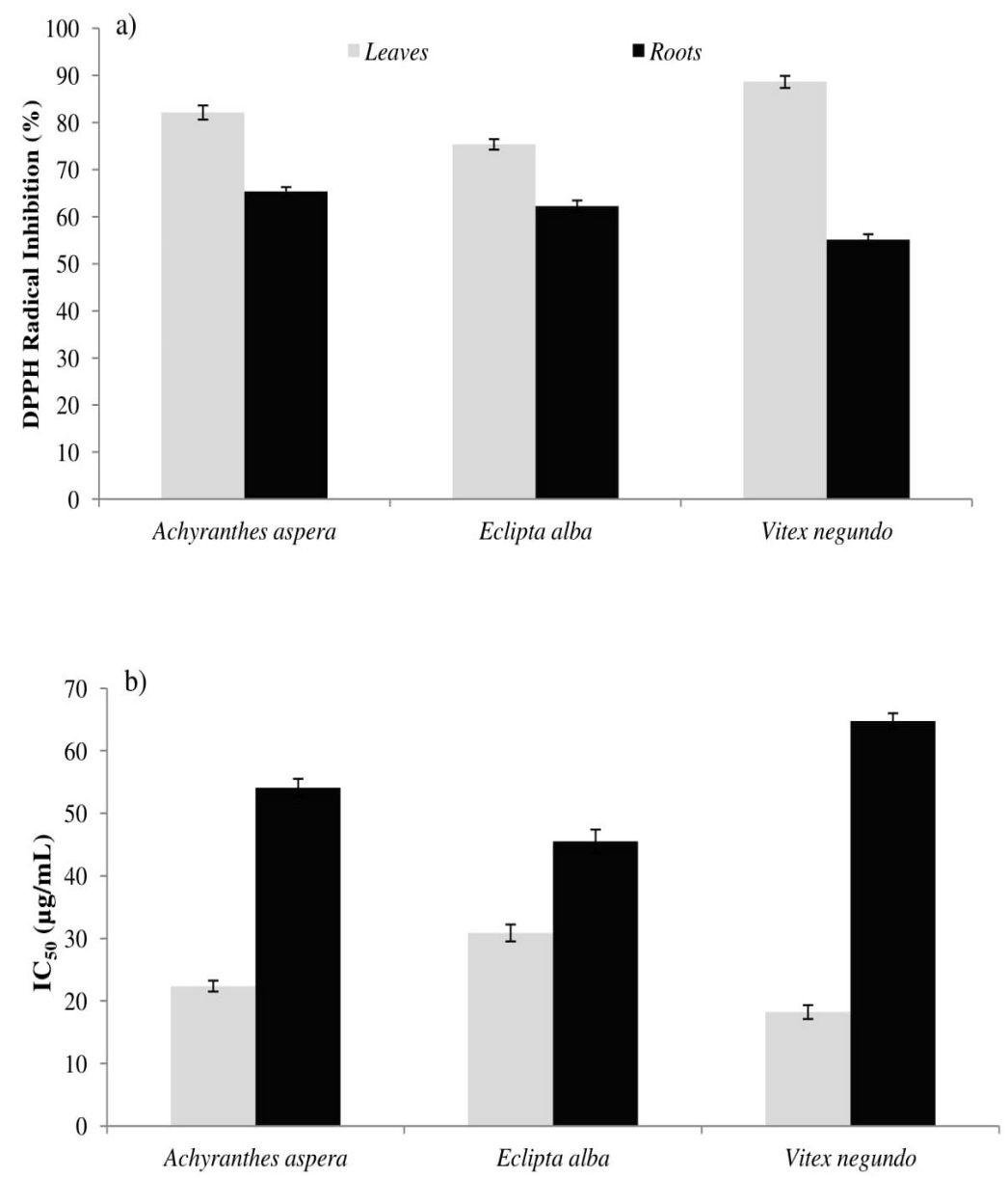

Figure 2. (\%) inhibition of 2, 2-diphenyl-1-picrylhydrazyl radical (DPPH) free radical (a) and $\mathrm{IC}_{50}$ (b) value of the samples.

Table 3. Pearson correlation and corresponding $p$-values among variables.

\begin{tabular}{|c|c|c|c|c|c|c|}
\hline \multicolumn{7}{|c|}{ Correlation Matrix } \\
\hline Variables & TPC & TFC & TEAC & DPPH & FRAP & $\alpha$-Amylase \\
\hline TPC & & 0.916 & 0.996 & 0.906 & 0.996 & 0.974 \\
\hline TFC & 0.916 & & 0.916 & 0.829 & 0.884 & 0.876 \\
\hline TEAC & 0.996 & 0.916 & & 0.914 & 0.988 & 0.966 \\
\hline $\mathrm{DPPH}$ & 0.906 & 0.829 & 0.914 & & 0.883 & 0.963 \\
\hline FRAP & 0.996 & 0.884 & 0.988 & 0.883 & & 0.967 \\
\hline$\alpha$-amylase & 0.974 & 0.876 & 0.966 & 0.963 & 0.967 & \\
\hline \multicolumn{7}{|c|}{$p$-Values } \\
\hline Variables & TPC & TFC & TEAC & DPPH & FRAP & $\alpha$-Amylase \\
\hline TPC & & $<0.0001$ & $<0.0001$ & $<0.0001$ & $<0.0001$ & $<0.0001$ \\
\hline TFC & $<0.0001$ & & $<0.0001$ & $<0.0001$ & $<0.0001$ & $<0.0001$ \\
\hline TEAC & $<0.0001$ & $<0.0001$ & & $<0.0001$ & $<0.0001$ & $<0.0001$ \\
\hline $\mathrm{DPPH}$ & $<0.0001$ & $<0.0001$ & $<0.0001$ & & $<0.0001$ & $<0.0001$ \\
\hline FRAP & $<0.0001$ & $<0.0001$ & $<0.0001$ & $<0.0001$ & & $<0.0001$ \\
\hline$\alpha$-amylase & $<0.0001$ & $<0.0001$ & $<0.0001$ & $<0.0001$ & $<0.0001$ & \\
\hline
\end{tabular}


Plants rich in secondary metabolites including phenolics and flavonoids demonstrate powerful antioxidant properties, both in vitro and in vivo, which is attributed to their redox properties and chemical structures [35-37]. The results of the previous studies are also similar to ours [28,30-33,38]. Several studies reported a strong correlation between antioxidant activity and TPC, indicating the importance of polyphenols as a potent antioxidant component, which is emerging as a trend in numerous plant varieties [28,30-33,38]. In this study, we also observed that the higher TPC of the plant extracts resulted in higher antioxidant activity; moreover, we found that the relationship between the antioxidant capacity and phenolic compounds of the extracts was positively correlated (Table 3), accordingly signifying that phenolic compounds are major contributors to the antioxidant activity of the selected plant samples. Antioxidant molecules can neutralize the reactive free radicals and prevent the progression of chronic diseases, including diabetes, cancers, cardiovascular diseases, neurodegeneration, and inflammatory mediated diseases. Antioxidant activity from foods is normally generated from the combination of several compounds rather than a specific single compound, and hence it is difficult to relate the antioxidant activity to a specific compound [31]. Therefore, a diet supplemented with different wild plants can supply different antioxidant molecules and subsequently provides preventive measures. Thus, these wild edible plants, as a source of rich antioxidant compounds, should be brought to the attention of the general population as important health-promoting foods. Since this is the first study on the antioxidant activity of the selected plants, a detailed phytochemical analysis is an absolute necessity to isolate the active phenolic and flavonoid components.

\section{5. $\alpha$-Amylase Inhibitory Activity of the Selected Plants}

The potential of the plant extracts to inhibit $\alpha$-amylase activity was analyzed (Figure 3$)$. The result revealed that the Vitex negundo leaf extract showed the highest inhibitory activity against $\alpha$-amylase (70.95\% inhibition) whereas the leaf extracts of Achyranthes aspera and Eclipta alba inhibited $\alpha$-amylase by $64.49 \%$ and $56.16 \%$, respectively. The lowest inhibitory activity ( $8.05 \%$ inhibition) was observed in the root extract of Vitex negundo. These plant extracts, especially the leaf extracts, showed appreciable $\alpha$-amylase inhibitory effects when compared with acarbose and their root counterparts (Figure 3 ). Olubomehin et al. [39] also found higher $\alpha$-amylase inhibition by the leaf compared to root of a traditional Nigerian plant. From Table 3, it can also be seen that the phenolic compounds exhibited significant correlation in inhibiting $\alpha$-amylase activity. This result is also comparable to previous study findings using other Bangladeshi [40], Indian [41], and Egyptian wild plants [26]. On the other hand, some authors reported no significant inhibition on $\alpha$-amylase activity by traditional plants [42]. Restraining or limiting the activity of $\alpha$-amylase is one of the approaches in the prevention and/or management of type- 2 diabetes. The inhibition of $\alpha$-amylase delays carbohydrate absorption after food ingestion and thereby decreases the rate of glucose production and eventually lowers blood glucose levels [19]. Therefore, the leaves of wild plants used in this study could be used as functional food ingredients for regulating and maintaining carbohydrate metabolism and postprandial hyperglycemia.

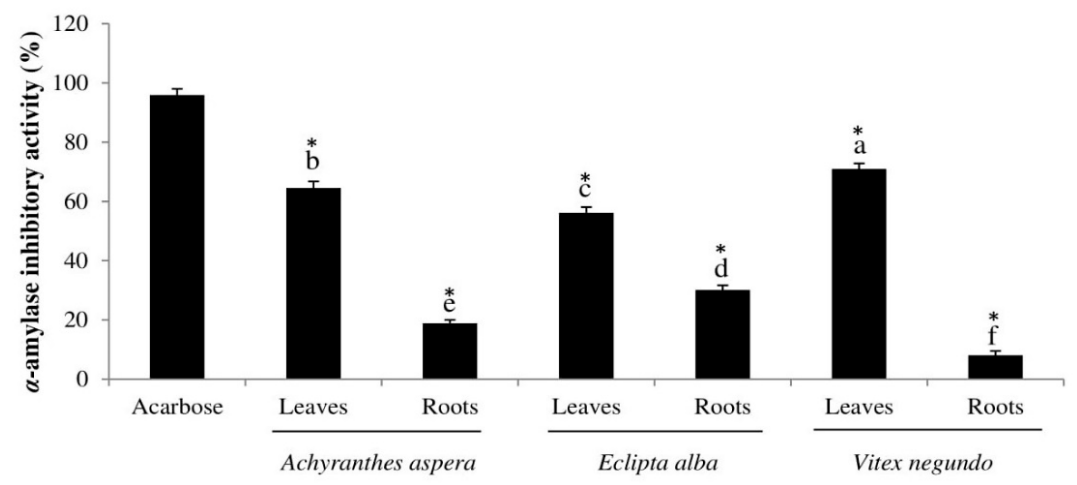

Figure 3. $\alpha$-amylase inhibitory activity (\%) of acarbose and the selected plant samples. Means that do not share a letter among samples are significantly different. ${ }^{*} p<0.05$ compared to acarbose. 


\subsection{Principal Component Analysis}

PCA analysis of pooled proximate variables, antioxidant activities, total phenolic content, total flavonoid content and $\alpha$-amylase activity of the selected wild plants was carried out. In the PCA analysis, the first two principal components explained about $86.05 \%$ of the total variance (Figure 4 ): PC1 $(77.09 \%)$ and PC2 $(8.96 \%)$. The $\mathrm{IC}_{50}$ and $\mathrm{CHO}$ were negatively associated with PC1, whereas the loadings on PC2 specified high contributions from DPPH and $\mathrm{Cu}$, with negative and positive values, respectively.
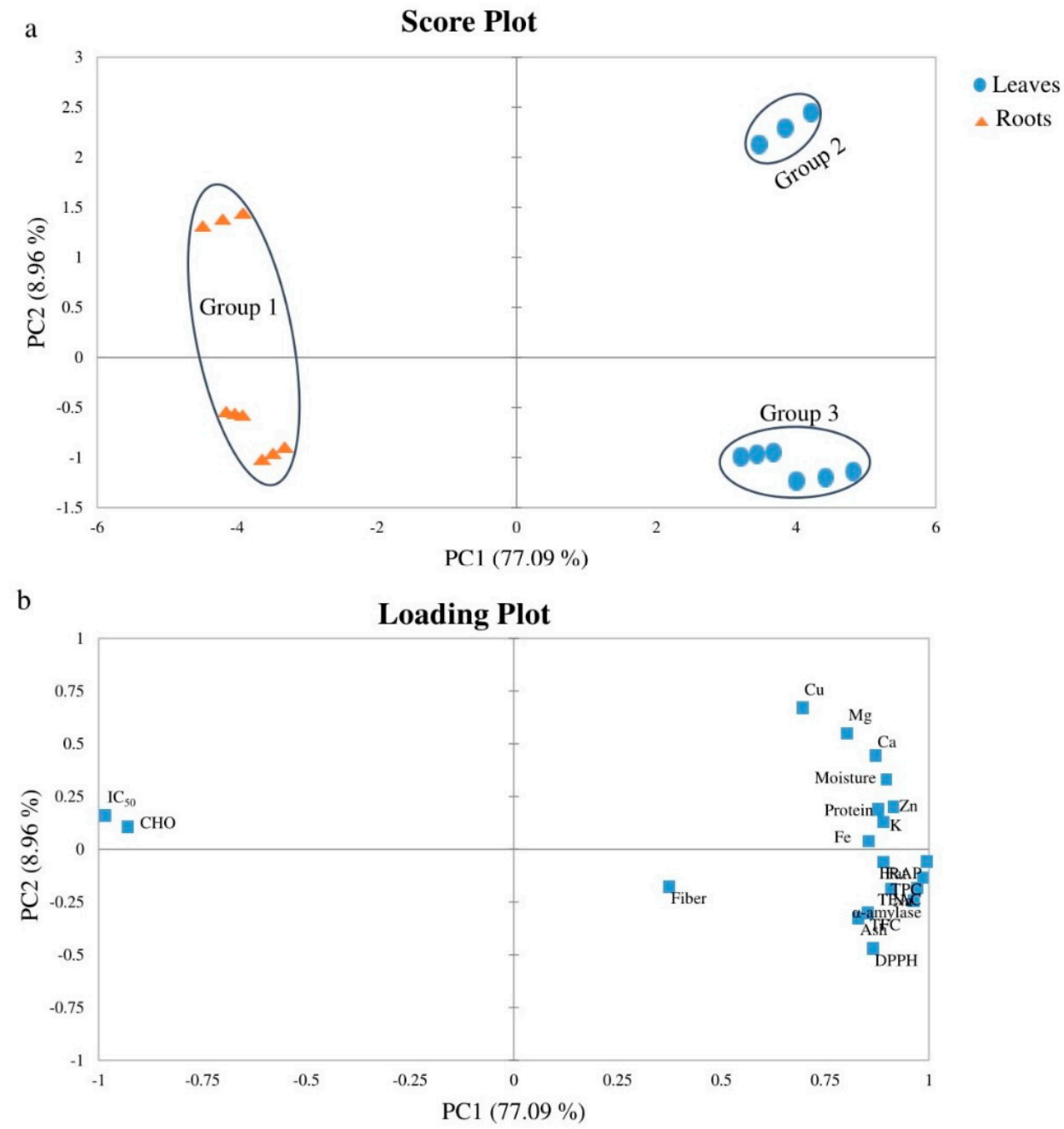

Figure 4. Score (a) and loading (b) plots of PCA analysis for the first and second components of selected plants.

Figure $4 \mathrm{a}, \mathrm{b}$ represents the score and loading plots of analyzed variables of the plant samples, respectively. In Figure 4a, a clear separation between the leaves and roots of the analyzed sample was observed. Also, in Figure 4a, the formation of three groups can be seen. Group 1 consists of roots of Vitex negundo, Achyranthes aspera \& Eclipta alba. Groups 2 \& 3 consist of leaves of Eclipta alba, and Achyranthes aspera \& Vitex negundo, respectively. $\mathrm{IC}_{50}$ and $\mathrm{CHO}$ variables contributed mostly to the separation of group 1, moisture, protein and all of the minerals except sodium for group 2, and TPC, TFC, $\alpha$-amylase, antioxidant activities (DPPH, FRAP \& TEAC), sodium, fat, protein, ash and fiber for group 3. 


\section{Conclusions}

The results suggest that the leaves and roots of Achyranthes aspera, Eclipta alba and Vitex negundo are a promising source of fiber, protein, minerals, antioxidant molecules and could serve as material for dietary supplementation and functional food ingredients. Our investigation of the selected plants also provides in vitro evidence of $\alpha$-amylase inhibition and justifies their use in the management of diabetes. However, the isolation of active compounds and the in vivo antidiabetic potential of these plants warrant further studies.

Author Contributions: Conceptualization, M.K.A. and M.A.; Methodology, Z.H.R., M.K.A. and M.A.; Software, Z.H.R. and M.K.A.; Validation, Z.H.R., M.K.A. and M.A.; Formal Analysis, Z.H.R., M.K.A. and M.A.; Investigation, Z.H.R. and M.K.A.; Resources, M.A.; Data Curation, Z.H.R. and M.K.A.; Writing-Original Draft Preparation, Z.H.R. and M.K.A.; Writing-Review \& Editing, Z.H.R., M.K.A. and M.A.; Visualization, Z.H.R., M.K.A. and M.A.; Supervision, M.A.; Project Administration, M.K.A. and M.A.

Funding: The authors received no financial support for this research and publication of this article.

Acknowledgments: The authors would like to extend their gratitude to Taxonomist Maksuda Khatun, Department of Botany, University of Dhaka, for the identification of plant material.

Conflicts of Interest: The Authors declare that there is no conflict of interest.

\section{References}

1. Johnsen, S.P.; Overvad, K.; Stripp, C.; Tjønneland, A.; Husted, S.E.; Sørensen, H.T. Intake of fruit and vegetables and the risk of ischemic stroke in a cohort of danish men and women. Am. J. Clin. Nutr. 2003, 78, 57-64. [CrossRef] [PubMed]

2. Vauzour, D.; Vafeiadou, K.; Rendeiro, C.; Corona, G.; Spencer, J.P.E. The inhibitory effects of berry-derived flavonoids against neurodegenerative processes. J. Berry Res. 2010, 1, 45-52. [CrossRef]

3. Murimi, M.W.; Kanyi, M.G.; Mbogori, T.N.; Amin, M.R.; Rana, Z.H.; Nguyen, B.; Moyeda-Carabaza, A.F. Voices and perspectives of rural hispanic households on food insecurity in west texas: A qualitative study. $J$. Hunger Environ. Nutr. 2018, 1-18. [CrossRef]

4. Afolayan, A.J.; Jimoh, F.O. Nutritional quality of some wild leafy vegetables in South Africa. Int. J. Food Sci. Nutr. 2009, 60, 424-431. [CrossRef] [PubMed]

5. Gupta, S.; Jyothi Lakshmi, A.; Manjunath, M.N.; Prakash, J. Analysis of nutrient and antinutrient content of underutilized green leafy vegetables. LWT-Food Sci. Technol. 2005, 38, 339-345. [CrossRef]

6. Nguyen, B.; Murimi, M.; Rana, Z.; Lee, H.; Halloran, R. Impact of a nutrition education intervention on nutrition knowledge and dietary intake of fruits, vegetables, and milk among fourth and fifth-grade elementary school children. J. Nutr. Educ. Behav. 2016, 48, S79. [CrossRef]

7. Dasgupta, N.; De, B. Antioxidant activity of some leafy vegetables of India: A comparative study. Food Chem. 2007, 101, 471-474. [CrossRef]

8. Alam, M.K.; Rana, Z.H.; Akhtaruzzaman, M. Chemical composition and fatty acid profile of Bangladeshi beef at retail. Int. Food Res. J. 2017, 24, 1897-1902.

9. Alam, M.K.; Rana, Z.H.; Akhtaruzzaman, M. Comparison of muscle and subcutaneous tissue fatty acid composition of Bangladeshi nondescript deshi bulls finished on pasture diet. J. Chem. 2017, 2017, 8579387. [CrossRef]

10. van Hecke, T.; van Camp, J.; de Smet, S. Oxidation during digestion of meat: Interactions with the diet and helicobacter pylori gastritis, and implications on human health. Compr. Rev. Food Sci. Food Saf. 2017, 16, 214-233. [CrossRef]

11. Ferguson, L.R. Chronic inflammation and mutagenesis. Mutat. Res. Fundam. Mol. Mech. Mutagen. 2010, 690, 3-11. [CrossRef] [PubMed]

12. Gülçin, I. Antioxidant activity of food constituents: An overview. Arch. Toxicol. 2012, 86, 345-391. [CrossRef] [PubMed]

13. Kumar, S.; Prasad, A.K.; Iyer, S.V.; Vaidya, S.K. Systematic pharmacognostical, phytochemical and pharmacological review on an ethno medicinal plant, Basella alba L. J. Pharmacogn. Phyther. 2013, 5, 53-58. 
14. Aprile, A.; Negro, C.; Sabella, E.; Luvisi, A.; Nicolì, F.; Nutricati, E.; Vergine, M.; Miceli, A.; Blando, F.; De Bellis, L. Antioxidant activity and anthocyanin contents in olives (cv cellina di nardò) during ripening and after fermentation. Antioxidants 2019, 8, 138. [CrossRef] [PubMed]

15. Coelho, E.M.; de Souza, M.E.A.O.; Corrêa, L.C.; Viana, A.C.; de Azevêdo, L.C.; dos Santos Lima, M. Bioactive compounds and antioxidant activity of mango peel liqueurs (Mangifera indica L.) produced by different methods of maceration. Antioxidants 2019, 8, 102. [CrossRef] [PubMed]

16. Armendáriz-Fernández, K.; Herrera-Hernández, I.; Muñoz-Márquez, E.; Sánchez, E. Characterization of bioactive compounds, mineral content, and antioxidant activity in bean varieties grown with traditional methods in Oaxaca, Mexico. Antioxidants 2019, 8, 26. [CrossRef] [PubMed]

17. Nwosu, F.; Morris, J.; Lund, V.A.; Stewart, D.; Ross, H.A.; McDougall, G.J. Anti-proliferative and potential anti-diabetic effects of phenolic-rich extracts from edible marine algae. Food Chem. 2011, 126, 1006-1012. [CrossRef]

18. Mojica, L.; Meyer, A.; Berhow, M.A.; de Mejía, E.G. Bean cultivars (Phaseolus vulgaris L.) have similar high antioxidant capacity, in vitro inhibition of $\alpha$-amylase and $\alpha$-glucosidase while diverse phenolic composition and concentration. Food Res. Int. 2015, 69, 38-48. [CrossRef]

19. Hanhineva, K.; Törrönen, R.; Bondia-Pons, I.; Pekkinen, J.; Kolehmainen, M.; Mykkänen, H.; Poutanen, K. Impact of dietary polyphenols on carbohydrate metabolism. Int. J. Mol. Sci. 2010, 11, 1365-1402. [CrossRef]

20. Satter, M.M.A.; Khan, M.M.R.L.; Jabin, S.A.; Abedin, N.; Islam, M.F.; Shaha, B. Nutritional quality and safety aspects of wild vegetables consume in Bangladesh. Asian-Pac. J. Trop. Biomed. 2016, 6, 125-131. [CrossRef]

21. Ocvirk, S.; Kistler, M.; Khan, S.; Talukder, S.H.; Hauner, H. Traditional medicinal plants used for the treatment of diabetes in rural and urban areas of Dhaka, Bangladesh-An ethnobotanical survey. J. Ethnobiol. Ethnomed. 2013, 9, 43. [CrossRef] [PubMed]

22. Alam, M.; Rana, Z.; Islam, S. Comparison of the proximate composition, total carotenoids and total polyphenol content of nine orange-fleshed sweet potato varieties grown in Bangladesh. Foods 2016, 5, 64. [CrossRef] [PubMed]

23. Shajib, M.T.I.; Kawser, M.; Nuruddin Miah, M.; Begum, P.; Bhattacharjee, L.; Hossain, A.; Fomsgaard, I.S.; Islam, S.N. Nutritional composition of minor indigenous fruits: Cheapest nutritional source for the rural people of Bangladesh. Food Chem. 2013, 140, 466-470. [CrossRef] [PubMed]

24. Alam, M.K.; Rana, Z.H.; Islam, S.N.; Akhtaruzzaman, M. Total phenolic content and antioxidant activity of methanolic extract of selected wild leafy vegetables grown in Bangladesh: A cheapest source of antioxidants. Potravin. Slovak J. Food Sci. 2019, 13, 287-293. [CrossRef]

25. Miao, J.; Li, X.; Zhao, C.; Gao, X.; Wang, Y.; Gao, W. Active compounds, antioxidant activity and $\alpha$-glucosidase inhibitory activity of different varieties of chaenomeles fruits. Food Chem. 2018, 248, 330-339. [CrossRef] [PubMed]

26. Hossain, S.; El-Sayed, M.; Aoshima, H. Antioxidative and anti- $\alpha$-amylase activities of four wild plants consumed by pastoral nomads in Egypt. Orient. Pharm. Exp. Med. 2009, 9, 217-224. [CrossRef]

27. Seal, T. Wild edible plants of arunachal pradesh: Ethnomedicinal and nutritional importance. Med. Plants 2018, 10, 1-9. [CrossRef]

28. Saikia, P.; Deka, D.C. Mineral content of some wild green leafy vegetables of north-east India. J. Chem. Pharm. Res. 2013, 5, 117-121.

29. Adedapo, A.A.; Jimoh, F.O.; Koduru, S.; Afolayan, A.J.; Masika, P.J. Antibacterial and antioxidant properties of the methanol extracts of the leaves and stems of Calpurnia aurea. BMC Complement. Altern. Med. 2008, 8, 53. [CrossRef]

30. Saklani, S.; Mishra, A.; Chandra, H.; Atanassova, M.; Stankovic, M.; Sati, B.; Shariati, M.; Nigam, M.; Khan, M.; Plygun, S.; et al. Comparative evaluation of polyphenol contents and antioxidant activities between ethanol extracts of Vitex negundo and Vitex trifolia L. leaves by different methods. Plants 2017, 6, 45. [CrossRef]

31. Shahat, A.A.; Ibrahim, A.Y.; Elsaid, M.S. Polyphenolic content and antioxidant activity of some wild Saudi Arabian asteraceae plants. Asian Pac. J. Trop. Med. 2014, 7, 545-551. [CrossRef]

32. Nana, F.W.; Hilou, A.; Millogo, J.F.; Nacoulma, O.G. Phytochemical composition, antioxidant and xanthine oxidase inhibitory activities of Amaranthus cruentus L. and Amaranthus hybridus L. extracts. Pharmaceuticals 2012, 5, 613-628. [CrossRef] [PubMed]

33. Hossain, S.; Shaheen, N.; Mohiduzzaman, M.; Banu, C.P. Antioxidant capacity and total phenol content of commonly consumed selected vegetables of Bangladesh. Malays. J. Nutr. 2011, 17, 377-383. 
34. Kaur, C.; Kapoor, H.C. Anti-oxidant activity and total phenolic content of some asian vegetables. Int. J. Food Sci. Technol. 2002, 37, 153-161. [CrossRef]

35. Mendoza-Wilson, A.M.; Castro-Arredondo, S.I.; Espinosa-Plascencia, A.; Del Refugio Robles-Burgueño, M.; Balandrán-Quintana, R.R.; Del Carmen Bermúdez-Almada, M. Chemical composition and antioxidant-prooxidant potential of a polyphenolic extract and a proanthocyanidin-rich fraction of apple skin. Heliyon 2016, 2. [CrossRef] [PubMed]

36. Geetha, S.; Ram, M.S.; Mongia, S.S.; Singh, V.; Ilavazhagan, G.; Sawhney, R.C. Evaluation of antioxidant activity of leaf extract of seabuckthorn (Hippophae rhamnoides L.) on chromium(vi) induced oxidative stress in albino rats. J. Ethnopharmacol. 2003, 87, 247-251. [CrossRef]

37. Woumbo, C.Y.; Kuate, D.; Womeni, H.M. Cooking methods affect phytochemical composition and anti-obesity potential of soybean (Glycine max) seeds in wistar rats. Heliyon 2017, 3. [CrossRef]

38. Petrus, A.J.A.; Kalpana, K.; Devi, A.B. Antioxidant capacity and lipophilic constitution of Alternanthera bettzickiana flower extract. Orient. J. Chem. 2014, 30, 491-499. [CrossRef]

39. Olubomehin, O.O.; Abo, K.A.; Ajaiyeoba, E.O. Alpha-amylase inhibitory activity of two anthocleista species and in vivo rat model anti-diabetic activities of Anthocleista djalonensis extracts and fractions. J. Ethnopharmacol. 2013, 146, 811-814. [CrossRef]

40. Uddin, N.; Hasan, M.R.; Hossain, M.M.; Sarker, A.; Hasan, A.H.M.N.; Islam, A.F.M.M.; Chowdhury, M.M.H.; Rana, M.S. In vitro $\alpha$-amylase inhibitory activity and in vivo hypoglycemic effect of methanol extract of Citrus macroptera Montr. fruit. Asian-Pac. J. Trop. Biomed. 2014, 4, 473-479. [CrossRef]

41. Rao, P.S.; Mohan, G.K. In vitro alpha-amylase inhibition and in vivo antioxidant potential of Momordica dioica seeds in streptozotocin-induced oxidative stress in diabetic rats. Saudi J. Biol. Sci. 2017, 24, 1262-1267. [CrossRef] [PubMed]

42. Oyedemi, S.O.; Oyedemi, B.O.; Ijeh, I.I.; Ohanyerem, P.E.; Coopoosamy, R.M.; Aiyegoro, O.A. Alpha-amylase inhibition and antioxidative capacity of some antidiabetic plants used by the traditional healers in southeastern Nigeria. Sci. World J. 2017, 2017, 3592491. [CrossRef] [PubMed]

(C) 2019 by the authors. Licensee MDPI, Basel, Switzerland. This article is an open access article distributed under the terms and conditions of the Creative Commons Attribution (CC BY) license (http://creativecommons.org/licenses/by/4.0/). 